\title{
Analysis and assessment of innovation risks
}

\author{
Sergey Filko, Irina Filko, Galina Zolotareva, and Ilya Fedorenko \\ Siberian State University of Science and Technology named after Academician M.F. Reshetneva, 31 \\ Gazety Krasnoyarsky Rabochy Avenue, 660037 Krasnoyarsk, Russia
}

\begin{abstract}
Currently, innovation activity is one of the most risky, so the creation of effective models for assessing the risks of innovation processes is a very urgent task of economic analysis and innovation management. The article analyzes the features of identifying the risks of innovation activity. The factors that determine the choice of the methodology for assessing innovation risks are described. The author's methodology for assessing the risks of economic security of high-tech enterprises is presented. The successive stages of the process of risk analysis of innovative projects are highlighted. The result of the study is a description of the parameters of the methodology for assessing the risks of innovation activity, a system of key indicators of continuous control and controlled indicators that allow improving the efficiency of economic risk management of domestic enterprises. The results obtained can be used as a fundamental basis for the study of the development of the risk-controlling methodology.
\end{abstract}

\section{Introduction}

Modern trends in the development of innovation activities in the Russian Federation are inextricably linked with an increase in the degree of risks of the external and internal environment of enterprises as a result of the growth of global competition, weakening of state regulation, total informatization, and other factors [1].

These circumstances and factors have caused the recent decades to be characterized by an increasing interest in risk management issues on the part of scientists and the management of high-tech enterprises.

However, it can be stated that a number of fundamentally important theoretical and methodological issues of risk management have not been fully resolved, and only a few of the works address the problems of risk management of innovative enterprises.

Enterprises engaged in innovative activities inevitably face an increased level of risks due to the specifics of their activities. The variety of risks is growing due to the increasing complexity of production technologies and the development of competition.

Despite the wide range of risks, it is possible to distinguish their universal specific categories, to which most innovative organizations are exposed. At the same time, it is necessary to take into account not only the nature of the organizations' activities (production, provision of services) but also the diversity of innovation activities. 


\section{Materials and methods}

There are many approaches to risk assessment, including those that implement various aspects of monitoring information and economic security. The issues of network management and the risk distribution models taking into account the structure and features of the systems [2,3] and the business process correctness analysis models [4] are interesting in the context of the problem under consideration. Taking into account the specifics of innovation risks, it is possible to consider them from the standpoint of assessing the relationship between risk and utility indicators, which are also successfully used in economic systems [5], or to apply assessment methods based on forecasting the level of risk, such as the Monte Carlo method [6]

Monitoring of risks associated with the development and implementation of innovative projects involves the development of an action plan aimed at reducing the level of risks in the implementation of the project and carrying out measures to optimize them.

When analyzing and assessing the risks of an innovation project, the main goal of any innovator is to find more rational, concise, and simple ways to solve problems. The optimization process is recommended to be carried out in stages in accordance with the following algorithm:

- selection and ranking of factors of the external and internal environment of the object and the subject of risk using the methods of factor analysis, mathematical-statistical and expert analysis;

- $\quad$ establishing relationships between the selected risk factors and the object of risk in terms of possible income, profit, or loss of funds;

- conducting risk optimization.

The basis of the economic security of the enterprise is a timely assessment of risks and prevention of the possibility of their implementation. There is no need to control all the risks but to monitor the most significant risks. The study of the scientific literature [1,7-9] showed that, despite all the diversity, the existing risk assessment methods are not adapted for high-tech enterprises. The choice of risk assessment methods makes sense only concerning a specific enterprise, following the specifics and scope of its activities, external and internal factors, and the information, financial, and tax policies implemented.

\section{Results and Discussion}

The proposed methodology for assessing the risks of innovative enterprises is presented in Figure 1. 


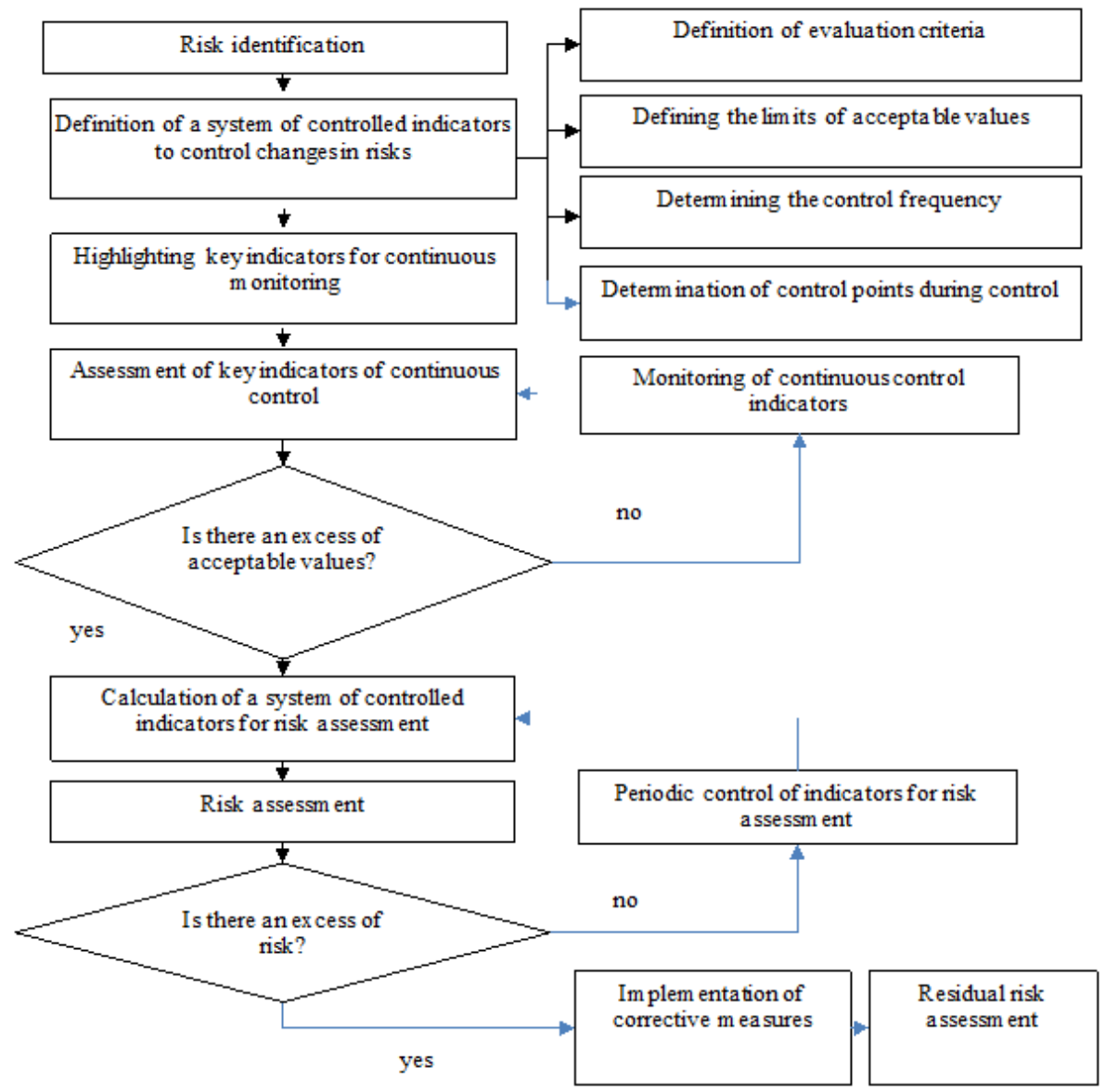

Fig. 1. Main stages of the risk assessment methodology of an enterprise engaged in innovation activities.

This methodology contains a sequence of specific actions that ensure both the risk identification and its subsequent assessment (after determining the criteria, the limits of acceptable values, the frequency of control, and the definition of control points), monitoring of key indicators, their assessment and possibility of implementing corrective measures. The initial stage associated with the identification of risks is the most responsible since it enables to determine the list of potential risks, make their preliminary assessment, and collect data to further assess the consequences of their implementation. At this stage, it is necessary to study the information about conditions that contribute to the risk emergence. For this purpose, it is necessary, on the one hand, to determine and study the duration and scale of the upcoming project work, while building a temporary map of the implementation of project stages for the innovation project, on the other hand - factors that affect the result of innovation activity (including external and internal factors, specifics of the activities of a particular enterprise), thereby ensuring the formation of a temporary map of risk localization during the implementation of stages of the innovation project (Figure 2). 


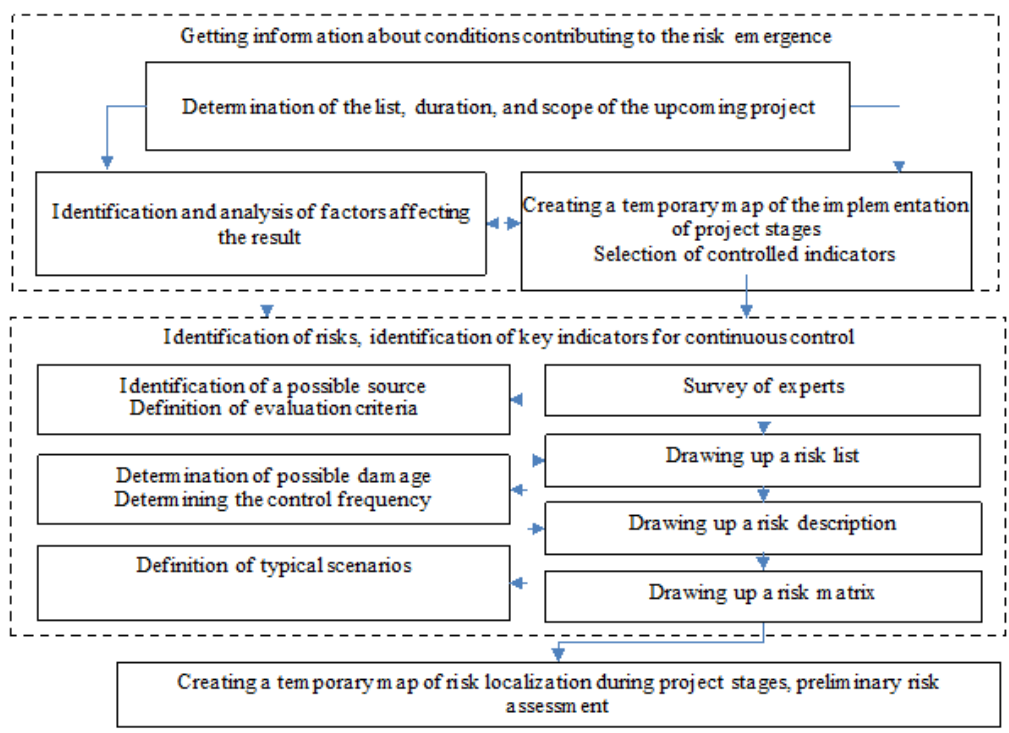

Fig.2. Main stages of identifying the risks of an innovative enterprise.

When identifying the risks of a particular enterprise, one can expertly select from these lists the factors that affect the result of innovation activity and the specific risks characteristic of this enterprise [10].

To solve these tasks, it is recommended to use questionnaires since they involve individual work of experts (but, in more complex cases, if necessary, one can use such techniques as interviewing, brainstorming, discussion or meeting).

First, one should determine the list of risks, then distribute the selected risks by putting their numbers on the temporary map of the project stages. It is recommended to: determine the risk source (check the possibility of influencing this source); determine the possible damage during the risk implementation and the probability of its implementation; determine typical scenarios and damage (identify a list of signs of adverse scenarios and damage) and form a risk matrix, determining the degree and level of response.

All this will help to determine the temporary localization of the risk on the map of the implementation of project stages (to identify the period of the greatest risk activity and further ranking).

Next, a preliminary risk assessment should be carried out to determine whether this risk should be included in the list of controlled risks. If the risk has signs that characterize its materiality, i.e. the possibility of the adverse scenario for the enterprise (real threat of damage), then it should be included in the list of controlled risks; if not, then the conditions that contribute to the risk emergence should be monitored, according to the results of which (if conditions change) a second check should be carried out for signs of adverse scenarios.

To assess the risks, it is recommended to define a system of controlled indicators, including:

- $\quad$ criteria for their assessment;

- limits of acceptable values;

- control frequency;

- control points during control.

In the course of the study, the indicators that can be used for control were selected for the identified risks of economic security of innovative enterprises, the criteria for their assessment, the limits of acceptable values, and other related parameters were determined. 
The recommended system of indicators developed for the most significant risks is presented in Table 1.

Table 1. Recommended system of controlled indicators.

\begin{tabular}{|c|c|c|c|c|}
\hline $\begin{array}{l}\text { Name of the } \\
\text { risk }\end{array}$ & Indicator & $\begin{array}{l}\text { Assessment } \\
\text { criteria }\end{array}$ & $\begin{array}{c}\text { Limits of } \\
\text { acceptable } \\
\text { values }\end{array}$ & $\begin{array}{c}\text { Control frequency/ } \\
\text { Control points during } \\
\text { control }\end{array}$ \\
\hline \multirow{3}{*}{$\begin{array}{l}\text { Risk of } \\
\text { solvency loss } \\
\text { due to lack of } \\
\text { funds for the } \\
\text { loan } \\
\text { repayment }\end{array}$} & $\begin{array}{c}\text { Cash inflow for the } \\
\text { period }\end{array}$ & $\begin{array}{l}\text { payment } \\
\text { amount }\end{array}$ & $\begin{array}{l}\geq \text { payment } \\
\text { amount }\end{array}$ & $\begin{array}{l}\text { Once a month/ Last day of } \\
\text { the month }\end{array}$ \\
\hline & $\begin{array}{l}\text { Cash outflow for the } \\
\text { period }\end{array}$ & $\begin{array}{c}\text { payment } \\
\text { amount }\end{array}$ & $\begin{array}{l}<\text { payment } \\
\text { amount }\end{array}$ & $\begin{array}{l}\text { Once a month/ Last day of } \\
\text { the month }\end{array}$ \\
\hline & Cash balance & $\begin{array}{l}\text { payment } \\
\text { amount }\end{array}$ & $\begin{array}{l}\geq \text { payment } \\
\text { amount }\end{array}$ & $\begin{array}{c}\text { Following the payment } \\
\text { schedule - the previous day } \\
\text { of the payment date/Before } \\
\text { the loan repayment }\end{array}$ \\
\hline \multirow{6}{*}{$\begin{array}{l}\text { Risk of } \\
\text { solvency loss } \\
\text { due to the } \\
\text { repayment } \\
\text { need/ } \\
\text { servicing } \\
\text { large loans or } \\
\text { a large } \\
\text { number of } \\
\text { loans }\end{array}$} & $\begin{array}{l}\text { Cash inflow for the } \\
\text { period }\end{array}$ & $\begin{array}{c}\text { payment } \\
\text { amount }\end{array}$ & $\begin{array}{l}\geq \text { payment } \\
\text { amount }\end{array}$ & $\begin{array}{c}\text { Once a month/ Last day of } \\
\text { the month }\end{array}$ \\
\hline & $\begin{array}{l}\text { Cash outflow for the } \\
\text { period }\end{array}$ & $\begin{array}{c}\text { payment } \\
\text { amount }\end{array}$ & $\begin{array}{l}<\text { payment } \\
\text { amount }\end{array}$ & $\begin{array}{l}\text { Once a month/ Last day of } \\
\text { the month }\end{array}$ \\
\hline & Cash balance & $\begin{array}{l}\text { payment } \\
\text { amount }\end{array}$ & $\begin{array}{l}\geq \text { payment } \\
\text { amount }\end{array}$ & $\begin{array}{c}\text { Following the payment } \\
\text { schedule }\end{array}$ \\
\hline & $\begin{array}{c}\text { Debt service coverage } \\
\text { ratio (DSCR) }\end{array}$ & Standard value & $\geq 1$ & $\begin{array}{l}\text { Quarterly/when reporting } \\
\text { or before receiving a loan }\end{array}$ \\
\hline & Credit load factor & Standard value & $<50 \%$ & constantly \\
\hline & $\begin{array}{l}\text { Debt overburden } \\
\text { coefficient }\end{array}$ & Standard value & $<50 \%$ & $\begin{array}{c}\text { monthly/Last day of the } \\
\text { month or before receiving a } \\
\text { loan }\end{array}$ \\
\hline
\end{tabular}

The recommended credit load factors (total amount of loans and interest on these loans available to the enterprise), debt overburden (ratio of monthly loan payment and monthly income), debt service (ratio of profit to interest payments for the period) should be included in the list of controlled indicators (and the credit load factor is also in the list of indicators of constant control) due to the fact that the risk of solvency loss due to the need to repay/service large loans or a large number of loans, due to insufficient (untimely) lending, as well as the possibility of damages or losses, solvency loss due to the possible refusal to provide a loan (and at the level of debt overburden of the enterprise more than $50 \%$, the probability of providing a new loan or restructuring on favorable terms is extremely small, and the emergence of additional requirements when obtaining new loans, a significant increase in loan rates, changes in the credit policy of banks in relation to the enterprise, which in turn leads to significant financial losses, increases sharply) are classified as significant risks that affect the economic security of the enterprise. The increase in the credit load factor is a warning signal (the closer it is to $100 \%$, the worse the situation) and indicates an increase in the risk of insolvency. The control of these indicators will ensure the exclusion of bankruptcy due to the excessive debt overburden of the enterprise.

To control the risks associated with obtaining a new loan or restructuring an old loan, it is necessary to ensure:

- constant monitoring of cash flow (since the bank's audit is carried out, as a rule, for the past three years, it should be ensured that the ratio of cash inflows and outflows is monitored for this period); 
- control of the ratio of the total cash flow and the amount of the client's debt obligations (cash flow coefficient, which characterizes the credit class of the enterprise);

- control of liquidity ratios (value of these coefficients will enable to assess the degree of possible risks of not granting a loan and determine the feasibility of using credit funds);

- monitoring the debt service coverage ratio (DSCR) - it is recommended to monitor not only the value of this indicator (it should be $\geq 1$ ) but also the trend of its change.

Other indicators can also be selected for monitoring. However, it is impractical to use the entire system of indicators for continuous control (monitoring), so it is recommended to identify and select, from this list of all controlled indicators, indicators of continuous control that are sensitive to changes in risks, which will enable to monitor the signs of adverse events and identify potential threats to the economic security of enterprises at an early stage.

Table 1 shows that the most sensitive indicator to the risk of solvency loss (lack of funds to repay the loan) among the three indicators is the "Cash Balance" indicator, which, when the actual balance decreases below the declared payment amount, indicates the presence of risk; and the smaller the balance, the higher the risk.

For continuous control indicators, assessment criteria and limits of permissible deviations are also defined (control frequency and definition of control points are not determined, taking into account the purpose of using indicators - monitoring).

In the following stages, the key indicators of continuous control and controlled indicators are assessed.

For continuous control indicators, assessment criteria and limits of permissible deviations are also defined (control frequency and definition of control points are not determined, taking into account the purpose of using indicators - monitoring).

In the following stages, the key indicators of continuous control and controlled indicators are assessed.

The key indicators are controlled continuously (monitoring). If it is possible to formalize this process, it is recommended to perform the calculation of indicators in automatic mode. It is recommended to use a special form of visual representation of the assessment results, which would ensure a different degree of accessibility of the resulting information for different levels of management. For example, for senior management, it is recommended to provide a graphical representation of the key indicators in comparison with the established criteria. For the head of the economic security department, a more complete report should be submitted, which will allow for a comparative analysis of the data in dynamics, etc. For specialists who monitor key indicators, it is recommended to submit a report-calculation by the type of attached files, which provides the formation of a general idea of the results obtained and the necessary detail of each result. The detected deviations are then analyzed for the presence of unacceptable deviations.

The presence of unacceptable deviations entails the calculation of controlled indicators, the analysis of which will allow us to conclude that corrective measures are necessary.

\section{Conclusions}

The proposed risk assessment methodology enables to program, plan, and implement effective anti-crisis management in the innovation sphere and form the basis for post-crisis progressive development by: balancing strategic and tactical actions for anti-crisis management; analyzing the tasks of forecasting, evaluation, optimization, etc.; competent measurement of resources and results; providing reliable and relevant information; information and analytical support for anti-crisis management; methodological and instrumental support for management. 


\section{References}

1. A. G. Badalova, Risk management system: methodology, organizational and information support, implementation efficiency, 121 (2007)

2. K. Beckers, I. Côté, S. Faßbender, M. Heisel, S. Hofbauer, Requirements for Engineering, 18(4), 343 (2013)

3. K. Beckers, Pattern and Security Requirements: Engineering-Based Establishment of Security Standards, 1 (2015)

4. A. Burattin, F. Maggi, A. Sperduti, Conformance checking based on multi-perspective declarative process models, Expert Systems with Applications, 65, 194 (2016)

5. A. Rubinstein, Lecture Notes in Microeconomic Theory, Princeton University Press, 153 (2013)

6. D. Petrone, V. Latora, Scientific Reports, 8(1), 5561 (2018)

7. V. LVasiliev, Kazan Economic Bulletin, 3(17), 90 (2015)

8. N. D. Ilienkova, Analysis and modern information technologies in ensuring the economic security of business and the state: a collection of scientific papers and results of joint research projects, 171 (2016)

9. R. A. Fatkhutdinov, Innovation management, 448 (2005)

10. S. V. Filko, I. V. Filko, Controlling, 1, 38 (2017) 